\title{
Levantamento etnobotânico de plantas medicinais utilizadas pelos moradores do povoado de Manejo, Lima Duarte - MG
}

\author{
OLIVEIRA, E.R. ${ }^{1 *}$; MENINI NETO, L. ${ }^{2}$ \\ ${ }^{1}$ Escola Estadual Tiago Delgado, Rua Nilo Delgado s/n, Manejo, CEP: 36140-000, Lima Duarte-Brasil *edina- \\ Id@hotmail.com ${ }^{2}$ Centro de Ensino Superior de Juiz de Fora, Campus Arnaldo Janssen, Luz Interior 345, Santa \\ Luzia, CEP: 36030-776, Juiz de Fora-Brasil
}

\begin{abstract}
RESUMO: O objetivo deste estudo foi o levantamento etnobotânico de plantas medicinais utilizadas pela população do povoado de Manejo, Lima Duarte (MG). O estudo foi realizado mediante visitas às casas dos moradores que responderam a questionário relacionado às espécies de plantas que são cultivadas, respectivas partes utilizadas, bem como as formas de preparo e quais doenças são tratadas com as plantas. Foram realizadas 41 visitas resultando em citações de 100 diferentes espécies medicinais, sendo a maioria cultivada nos quintais e outras nativas da região, as quais também são utilizadas pelos moradores. Exemplares foram coletados e depositados no herbário CESJ, da Universidade Federal de Juiz de Fora. As espécies mais citadas foram Mentha sp., Lippia alba (Mill.) N. E. Brown, Foeniculum vulgare Mill., Achyrocline satureioides (Lam.) DC., Bidens pilosa L., Mentha pulegium L., Mikania glomerata Spreng., Rosa sp. e Plantago major L. As doenças mais tratadas com as plantas medicinais em Manejo são gripes e resfriados, problemas estomacais, cólicas menstruais e infecções no útero, verminose, problemas renais, ansiedade e estresse. As partes mais utilizadas são as folhas, e a forma de preparo mais comum das plantas são os chás por infusão. A construção de horta comunitária no povoado pode valorizar o emprego das plantas medicinais, sobretudo pelos mais jovens, mantendo a tradição do uso pelas futuras gerações.
\end{abstract}

Palavras-chave: etnobotânica, plantas medicinais, Zona da Mata de Minas Gerais

\begin{abstract}
Ethnobotanical survey of the medicinal plants used by dwellers of Manejo Village, Lima Duarte-Minas Gerais State, Brazil. The aim of this study was the ethnobotanical survey of medicinal plants used by the population of Manejo Village, Lima Duarte (Minas Gerais State), Brazil. The study was performed by means of visitations to the houses of dwellers who answered a questionnaire related to the plant species that are cultivated, respective parts that are used, as well as preparation forms and which diseases are treated with the plants. A total of 41 visitations were done, resulting in citation of 100 different medicinal species, most of which were cultivated in backyards while others were native to that region, which were also used by the dwellers. Specimens were collected and deposited in CESJ herbarium, of the Federal University of Juiz de Fora. The most cited species were Mentha sp., Lippia alba (Mill.) N. E. Brown, Foeniculum vulgare Mill., Achyrocline satureioides (Lam.) DC., Bidens pilosa L., Mentha pulegium L., Mikania glomerata Spreng., Rosa sp. and Plantago major L. The diseases most treated with medicinal plants in Manejo Village are flu and cold, stomach disorders, menstrual cramps and uterus infections, helminth infections, kidney problems, anxiety and stress. The most used parts are leaves, and the most common form of plant preparation is infusion tea. The construction of a community garden in the village may value the use of medicinal plants, especially by the young, maintaining the tradition of their use by future generations.
\end{abstract}

Key words: ethnobotany, medicinal plants, Zona da Mata of Minas Gerais

\section{INTRODUÇÃO}

A humanidade faz uso das plantas medicinais desde o início da existência. Na zona rural a utilização das plantas medicinais sempre existiu onde os povos que aí vivem mantêm uma relação bastante harmoniosa com a natureza, pois dela retiram alimento, abrigo e, principalmente, remédios para aliviar as dores ou se curar de algum mal. Estas pessoas que sempre viveram no campo possuem

Recebido para publicação em 17/10/2010

Aceito para publicação em 28/11/2011

Rev. Bras. PI. Med., Botucatu, v.14, n.2, p.311-320, 2012. 
amplo conhecimento sobre a forma correta de usar as plantas medicinais e estão em constante e mútua troca de saberes (Amorozo, 2002).

As pesquisas etnobotânicas nestas comunidades rurais têm grande importância, principalmente em se tratando do Brasil, devido à grande riqueza da flora medicinal utilizada no país, a qual tem sido ameaçada em virtude das ações antrópicas que visam o extrativismo das plantas. Desse modo, há a necessidade da continuidade destes estudos como forma de contribuição à preservação de espécies medicinais (Fonseca \& Sá, 1997).

A etnobotânica, além de fazer o resgate das espécies de plantas utilizadas como remédio, também valoriza o conhecimento popular das comunidades (Amorozo et al., 1996) e, por meio de estudos desta natureza, as plantas medicinais podem ter as ações terapêuticas conhecidas para serem posteriormente comprovadas.

Atualmente o uso de plantas medicinais se encontra muito valorizado deixando de ser costume apenas da zona rural e chegando às cidades não só como uma maneira de auxiliar na medicina convencional, mas também sendo forma saudável de utilização de medicamentos (Almassy Junior et al., 2005).

O povoado de Manejo, localizado na zona rural do município de Lima Duarte, é privilegiado pela representatividade da flora medicinal na região com espécies espontâneas ou, na maioria dos casos, cultivada pelos moradores em quintais. Destaca-se também o projeto de construção de horta comunitária de plantas medicinais.

Como contribuição ao conhecimento do uso popular das ervas medicinais, este trabalho teve como metas: inventariar as plantas medicinais utilizadas pela população deste povoado, bem como apontar as formas de utilização.

\section{MATERIAL E MÉTODO}

O povoado de Manejo possui aproximadamente 376 habitantes e pertence ao município de Lima Duarte, situado a $45 \mathrm{Km}$ de Juiz de Fora, nas coordenadas 2143'38" S e 4343'43" W. Apresenta altitude média de $728 \mathrm{~m}$ e está situado entre o Planalto Itatiaia e o Planalto de Andrelândia (Instituto Brasileiro de Geografia e Estatística, 2007).

Duque de Caxias instalou-se nesta localidade em julho de 1842 para fazer maneabilidade de armas e o local ficou conhecido como "Manejo", permanecendo assim até hoje (Modesto, 1976). A principal atividade econômica do povoado é a agricultura de subsistência e a bovinocultura de leite devido à topografia plana que favorece esta prática.

Foi aplicado questionário semi-estruturado, composto por 17 perguntas relacionadas com a etnobotânica em visitas às residências de moradores que cultivam e fazem o uso das plantas medicinais. Os critérios utilizados para a escolha das pessoas a serem entrevistadas foram, principalmente: aquelas que cultivam as plantas medicinais e também aquelas que participam do projeto da horta comunitária de plantas medicinais.

Durante as visitas as pessoas fizeram relatos dos conhecimentos que detinham sobre as plantas, como por exemplo, de quem obtiveram o aprendizado do uso dos "remédios da horta", e as doenças que pais e avós tratavam com as plantas medicinais, pois, na época, nem todas as pessoas tinham acesso aos medicamentos industrializados acreditando também que as plantas ofereciam maiores benefícios à saúde.

Muitas entrevistas foram realizadas no próprio quintal dos moradores, os quais consideraram muito importante este tipo de estudo como forma de valorizar este saber. As plantas foram mostradas e os respectivos usos no tratamento de várias doenças foram apresentados.

Exemplares das plantas foram coletados e depositados no herbário da Universidade Federal de Juiz de Fora (CESJ), sendo o material testemunho citado pelo número de coleta da primeira autora (Tabela 1).

\section{RESULTADO E DISCUSSÃO}

Foram realizadas 41 entrevistas (Figura 1), representando aproximadamente $11 \%$ da população do povoado, com 100 citações de espécies diferentes, pertencentes à 33 famílias (Tabela 1). Dentre as espécies citadas, 35 são referidas na resolução da Agência Nacional de Vigilância Sanitária (ANVISA), que regulamentou uma lista de várias plantas medicinais de uso tradicional com efeito comprovado cientificamente, além das formas corretas de uso e contra-indicações das mesmas (ANVISA, 2010).

O número de depoimentos foi determinado segundo a proposta de Shardong \& Cervi (2000), os quais afirmaram que o número de citações de diferentes plantas por cada entrevistado auxilia na determinação da quantidade de entrevistas a serem realizadas, devendo ser interrompido quando ocorre estabilização. Dentre os 41 entrevistados, 34 foram mulheres, fato que ocorre devido à maioria das mulheres na zona rural permanecer em casa cuidando dos afazeres domésticos, dentre os quais está o cultivo das plantas medicinais, como destacado por Calábria et al. (2008). Foram entrevistados sete homens, que, por serem trabalhadores rurais possuem maiores conhecimentos das plantas de ocorrência espontânea na região, pois estas crescem próximas às áreas de cultivo.

O maior número de informações e conhecimentos sobre as plantas medicinais concentrou-se na faixa etária de 51-60 anos (Figura 


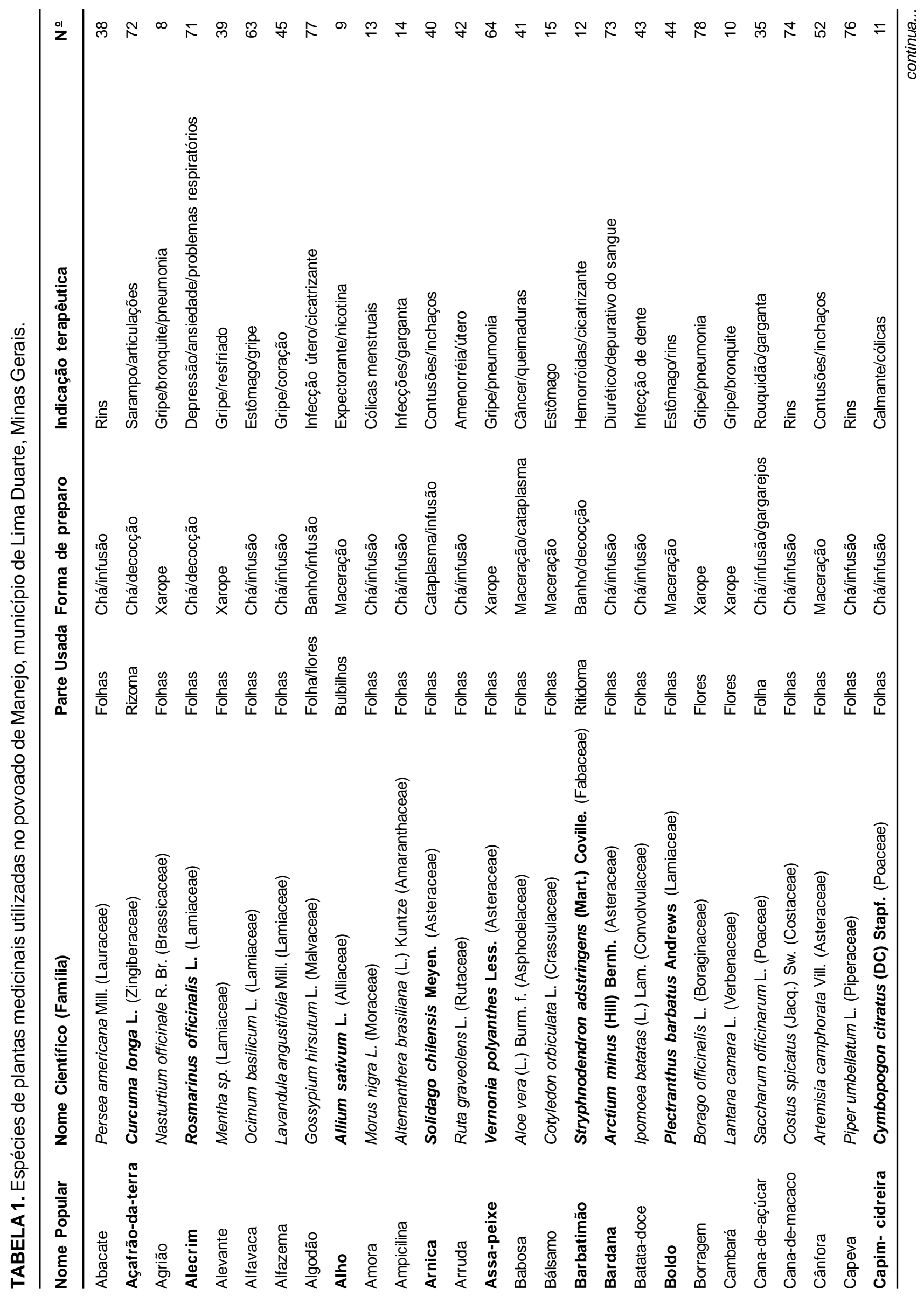

Rev. Bras. Pl. Med., Botucatu, v.14, n.2, p.311-320, 2012. 


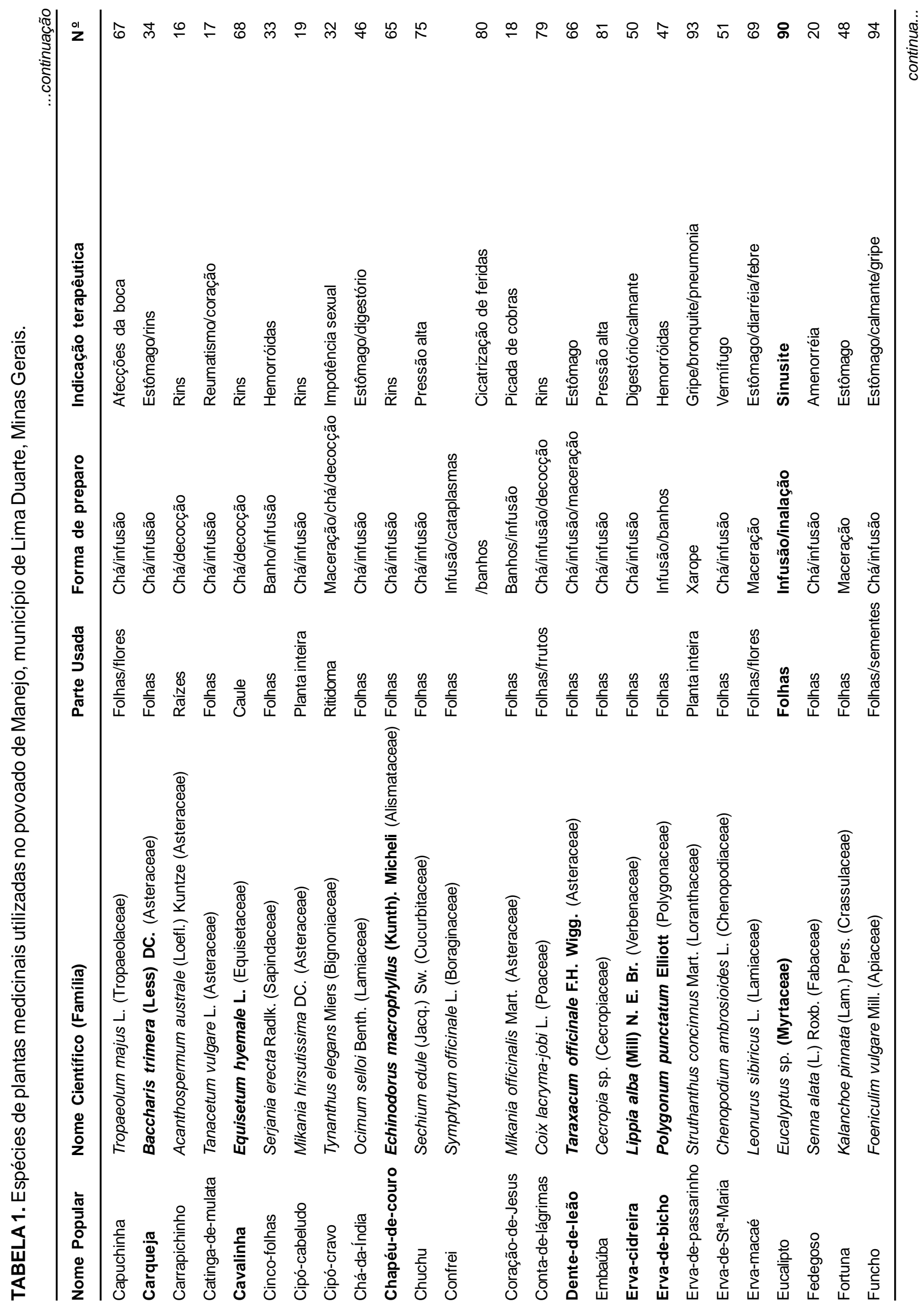

Rev. Bras. PI. Med., Botucatu, v.14, n.2, p.311-320, 2012. 


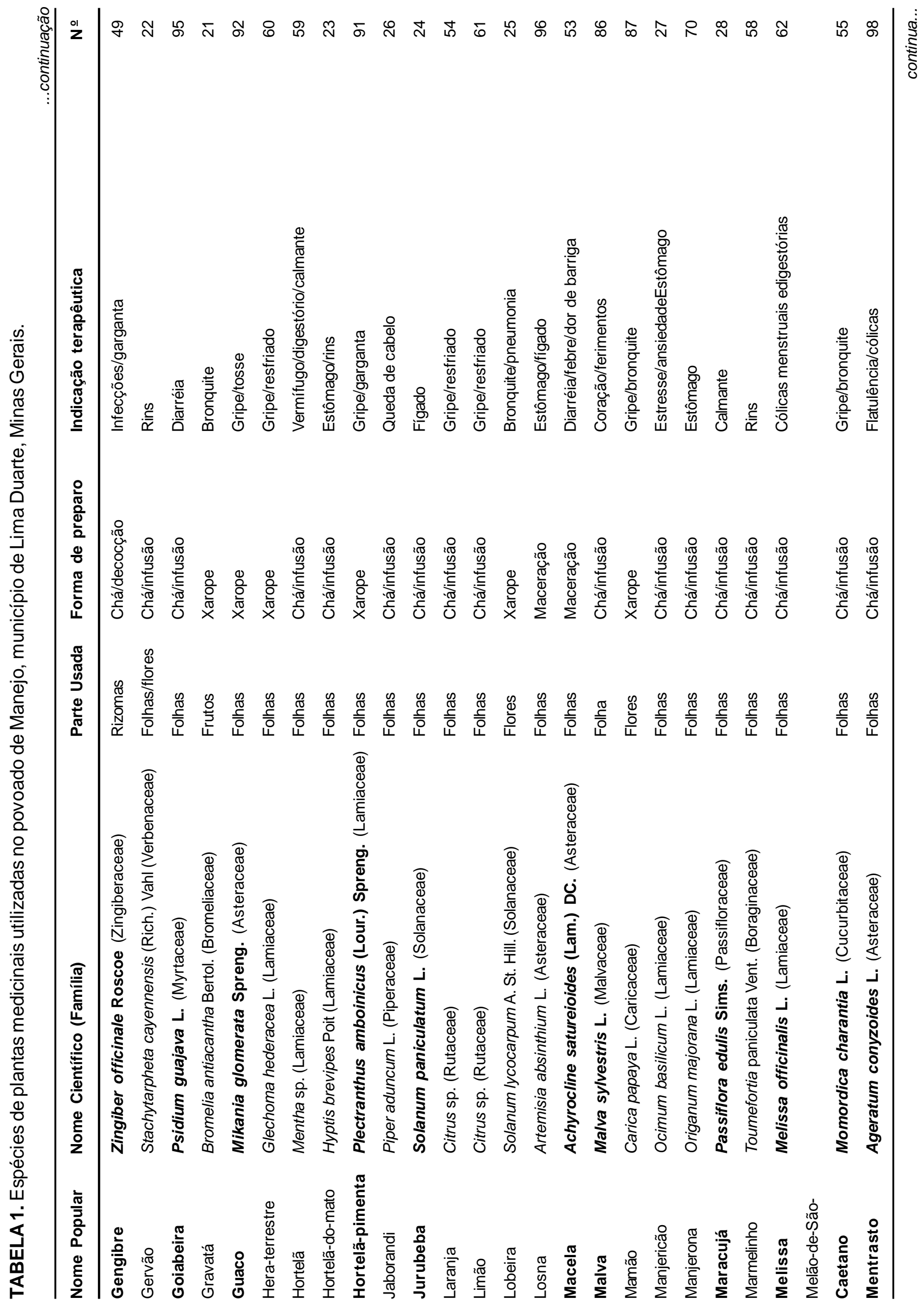

Rev. Bras. PI. Med., Botucatu, v.14, n.2, p.311-320, 2012. 


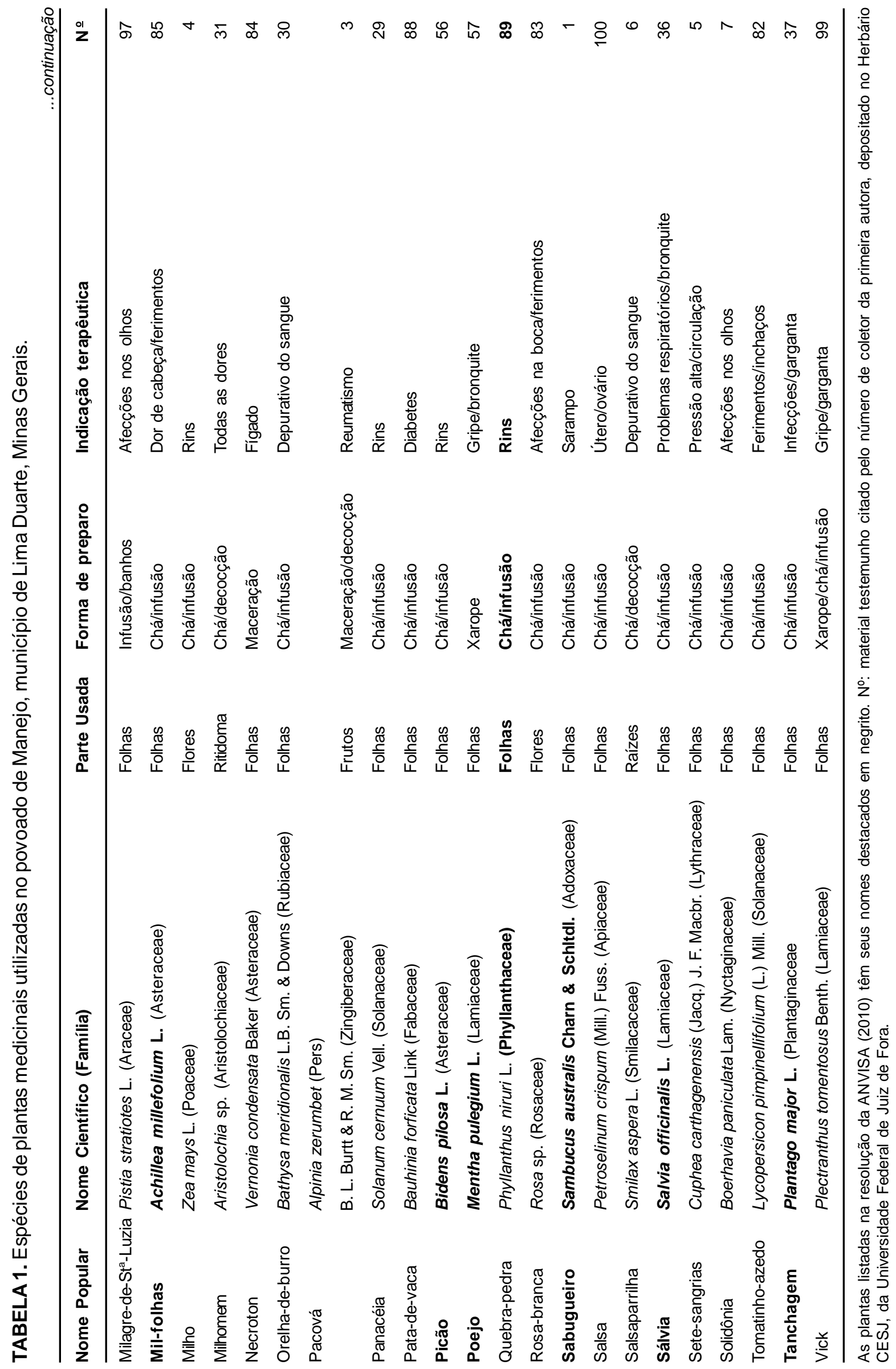

Rev. Bras. PI. Med., Botucatu, v.14, n.2, p.311-320, 2012. 


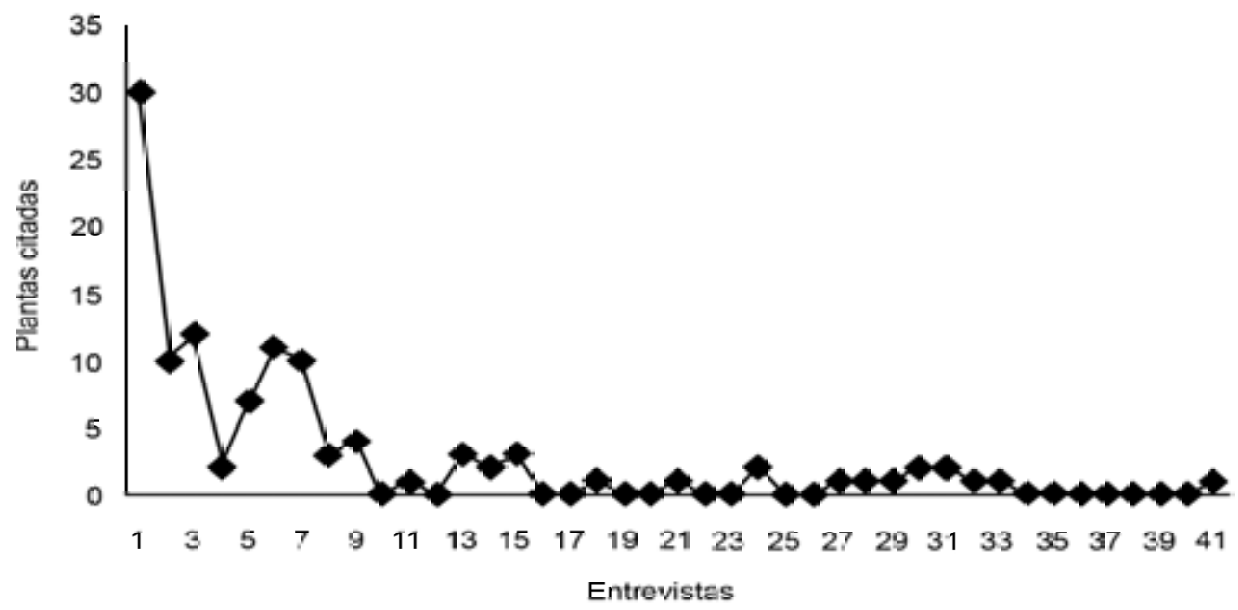

FIGURA 1. Número de plantas diferentes citadas por entrevista.

2), sofrendo leve decréscimo nas faixas posteriores. A maior concentração nesta faixa etária se justifica, pois são, em geral, integrantes do projeto da horta medicinal e as faixas etárias posteriores constituemse de pessoas que possuem principalmente os conhecimentos populares herdados dos antepassados. De acordo com as entrevistas, as pessoas mais jovens se interessam muito pouco pelo tratamento com as plantas medicinais, e, por isso, as desconhecem corroborando com os estudos de Phillips \& Gentry (1993) e de Amorozo et al. (1996).

A maioria dos entrevistados tinha nível de escolaridade baixo, pois o trabalho pesado ligado à agricultura inviabilizou a continuidade dos estudos; no entanto, muitas pessoas já participaram de cursos sobre o uso correto das plantas medicinais justificando a construção de horta comunitária exclusiva de plantas medicinais.

As famílias botânicas mais representativas foram Asteraceae e Lamiaceae, ambas com 17 citações, representando $34 \%$ das espécies. É freqüente a maior representatividade destas duas famílias em estudos etnobotânicos e/ou etnofarmacológicos como pode ser observado, por exemplo, em Castelucci et al. (2000), Marodin \& Baptista (2001), Parente \& Rosa (2001), Almeida \& Albuquerque (2002), Almassy Junior (2004), Pinto et al. (2006), Vendruscolo \& Mentz (2006) e Magalhães et al. (2009), pois ambas são famílias cosmopolitas com muitas espécies que se adaptaram bem, tanto aos ambientes tropicais quanto aos temperados, e que possem óleos essenciais variados, justificando esta representatividade.

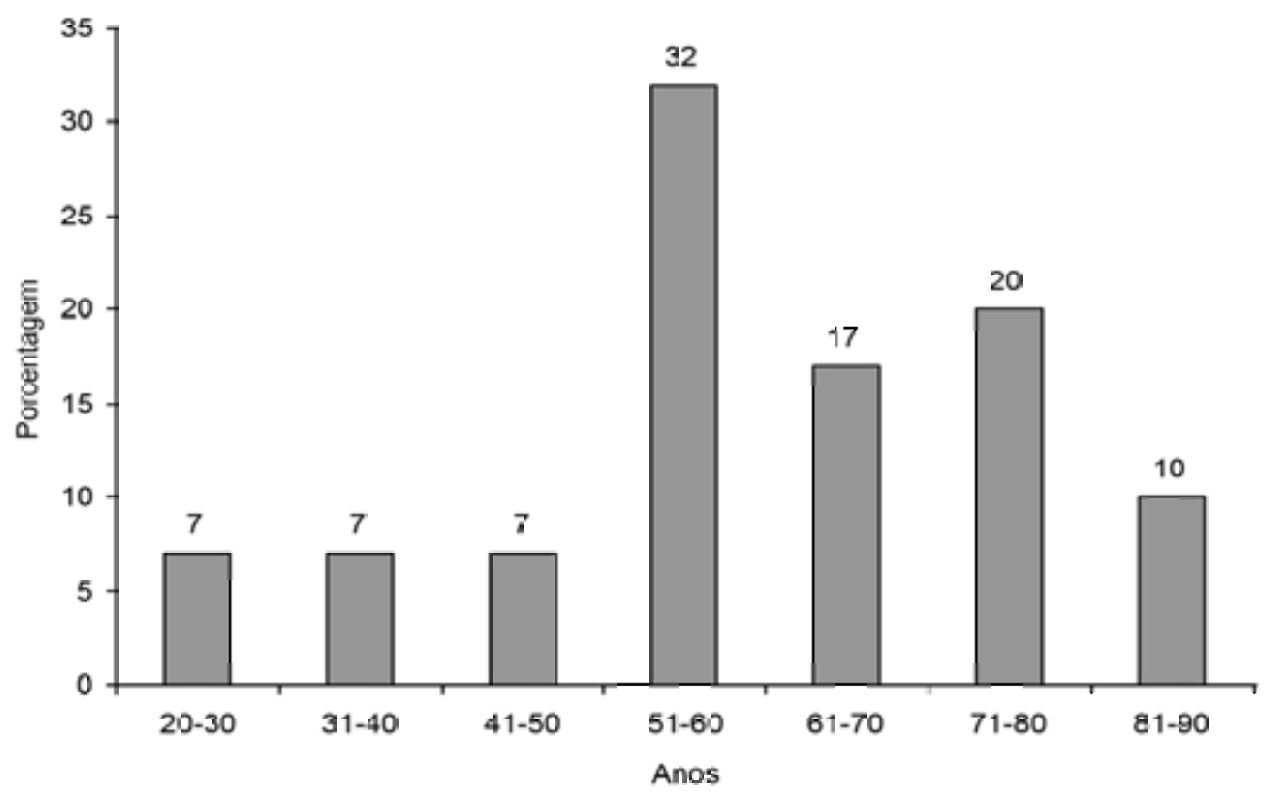

FIGURA 2. Faixa etária dos entrevistados. 
A espécie mais citada pelos entrevistados foi a hortelã (Mentha sp., Lamiaceae) com 20 citações, seguida de erva-cidreira de árvore (Lippia alba (Mill.) N. E. Brown, Verbenaceae) e o funcho (Foeniculum vulgare Mill., Apiaceae) com 19 citações cada, macela (Achyrocline satureioides (Lam.) DC., Asteraceae) citada 17 vezes, picão (Bidens pilosa L., Asteraceae) e poejo (Mentha pulegium L., Lamiaceae) com 15 citações cada, guaco (Mikania glomerata Spreng., Asteraceae) e rosa-branca (Rosa sp., Rosaceae) citadas 14 vezes, tanchagem (Plantago major L., Plantaginaceae) citada 12 vezes e alevante (Mentha sp., Lamiaceae) citada 11 vezes. Muitas destas são espécies comumente citadas em inventários dessa natureza, embora não na mesma ordem, como destacado nos estudos realizados por Silva et al. (2005), Calábria et al. (2008), Kffuri (2008) e Silva et al. (2009).

As partes das plantas mais utilizadas pelos entrevistados foram principalmente as folhas, representando $43 \%$ das citações, seguidas de flores, ritidoma e de frutos. Isso se deve ao fato das folhas serem coletadas com mais facilidade e serem encontradas em praticamente o ano todo, corroborando com as observações de Castellucci et al. (2000), Pereira et al. (2004) e Silva et al. (2009). Deste modo, ocorre também a conservação da planta para usos posteriores, pois não há impedimento do crescimento e reprodução do espécime com a coleta das folhas, como destacado por Silva et al. (2009).

A forma de preparo correto das plantas medicinais deve ser levado em consideração devido aos diferentes óleos essenciais voláteis presentes nas folhas, flores e outros órgãos da planta, segundo Almassy Júnior et al. (2005). O Eugenol, presente na alfavaca, é o composto responsável pelas ações biológicas (Matos, 2000). A forma de preparo mais utilizada no povoado de Manejo é o chá, por infusão, corroborando com os estudos de Corrêa Junior et al. (1994) e Kffuri (2008). A maceração, banhos, inalação, pomada e cataplasma são as demais formas de uso.

Grande parte dos entrevistados afirmou que faz uso das plantas medicinais sempre que é preciso, e também por acreditar que elas não fazem mal à saúde. Sempre que alguém na família adoece e o problema é considerado de menor gravidade, a primeira atitude é recorrer aos chás, xaropes e outros. Caso o tratamento inicial não obtenha bons resultados, o médico é então procurado. Esta forma de agir também foi observada no município de Santo Antônio de Leverger, no Mato Grosso, por Amorozo (2002). Não é hábito a utilização das plantas associadas aos medicamentos industrializados, por temerem que essa associação cause algum dano ao organismo, confirmando os dados obtidos por MenonMiyake et al. (2004).

Chama a atenção a forma de uso do melão-
de-São-Caetano (Momordica charantia L., Cucurbitaceae) no povoado de Manejo. Esta planta é utilizada no preparo de xaropes no combate à gripes e bronquites, mas, segundo Duke (1989) e Martins et al. (1994), a mesma possui ações emenagoga, purgativa, e anti-helmíntica. Já de acordo com a resolução da Agência Nacional de Vigilância Sanitária (ANVISA), o melão-de-são-caetano é utilizado para dermatites (irritação da pele) e escabiose (sarna), não devendo ser usado por via oral devido à reações adversas, tais como coma hipoglicêmico e convulsões em crianças, dor de cabeça e problemas hepáticos (ANVISA, 2010).

Dentre as 41 entrevistas realizadas, em $68 \%$ delas o aprendizado de uso das plantas medicinais ocorreu através das pessoas mais velhas da família, fato comumente observado em estudos semelhantes (Ming \& Amaral Junior, 2005). No entanto, o povoado de Manejo tem uma particularidade que é o projeto de construção de horta de plantas medicinais, de modo que muitos habitantes também obtiveram os conhecimentos sobre as plantas através de cursos e livros, perfazendo $32 \%$ do total de entrevistados no presente estudo.

Quanto à dosagem foi comum observar que não há medida padronizada. Em geral, para os chás, comumente é citada a posologia de uma xícara três vezes ao dia e, para os xaropes, uma colher de sopa ou meio copo, também três vezes ao dia, até melhorar os sintomas da doença tratada. No entanto, ocorre variação de acordo com a experiência do entrevistado, como também observado por Calábria et al. (2008).

As quantidades utilizadas na confecção dos chás e xaropes são freqüentemente referidas como um punhado, seja da folha, flor ou sementes. As doenças mais tratadas com as plantas medicinais na comunidade, segundo os entrevistados, foram: gripes e resfriados, problemas renais, cólicas menstruais e problemas no útero, dor de barriga e diarréia, insônia e ansiedade, problemas estomacais. Resultados semelhantes também foram observados por Silva-Almeida \& Amorozo (1988), Hanazaki et al. (1996); Amorozo \& Gely (1988), em outros estudos realizados no Brasil.

É possível que esta falta de padronização ou desconhecimento acerca da dosagem de uso ou das quantidades empregadas na preparação dos medicamentos com as plantas reduza a eficácia ou até mesmo seja fonte de reações adversas advindas do uso incorreto.

\section{CONCLUSÃO}

Conclui-se que é frequente o uso das plantas medicinais no povoado de Manejo; no entanto, esta utilização fica a cargo principalmente das pessoas mais velhas, pois os jovens possuem pouco

Rev. Bras. Pl. Med., Botucatu, v.14, n.2, p.311-320, 2012. 
conhecimento das plantas e preferem os medicamentos convencionais por oferecer um alívio mais rápido. Isto conduz à pouca valorização desta tradição por parte das pessoas desta faixa etária e, caso esta situação não se reverta, é possível que grande parte do conhecimento popular acerca do uso das plantas medicinais se perca com o tempo.

Por outro lado, a perspectiva da construção da horta comunitária aponta para maior valorização e consumo das plantas medicinais nesta comunidade, sobretudo pelas pessoas mais velhas. É também uma oportunidade para conduzir ao resgate do uso pelos mais jovens, mantendo-se assim a tradição do emprego das plantas medicinais nas futuras gerações do povoado, servindo também de exemplo para outras localidades que podem se beneficiar do desenvolvimento de projeto semelhante.

\section{AGRADECIMENTO}

Aos moradores do povoado de Manejo, que confiaram informações tão importantes, as quais foram a base da pesquisa. Aos dois revisores anônimos pelos comentários.

\section{REFERÊNCIA}

AGÊNCIA NACIONAL DE VIGILÂNCIA SANITÁRIA (ANVISA). Resolução no 10, de 9 de março de 2010. Dispõe sobre a notificação de drogas vegetais. Diário Oficial da República Federativa do Brasil, Brasília, n.46 p.52, 10 de março de 2010. Seção 1. Disponível em: <http:://www.anvisa.gov.br>. Acesso em: 14 mar. 2010. ALMASSY JÚNIOR, A.A. Análise das características etnobotânicas e etnofarmacológicas de plantas medicinais na comunidade de Lavras Novas, Ouro Preto-MG. 2004. 130p. Tese (Doutorado em Fitotecnia) Universidade Federal de Viçosa, Viçosa.

ALMASSY JÚNIOR, A.A. et al. Folhas de chá: plantas medicinais na terapêutica humana. Viçosa: Editora da Universidade Federal de Viçosa, 2005. 233p.

ALMEIDA, C.F.B.; ALBUQUERQUE, U.P. Uso e conservação de Plantas e animais medicinais no estado de Pernambuco (Nordeste do Brasil): um estudo de caso: Interciência, v.26, n.6, p.276-85, 2002.

AMOROZO, M.C.M. Uso e diversidade de plantas medicinais em Santo Antônio do Leverger, MT, Brasil. Acta Botanica Brasilica, v.16, n.2, p.189-203, 2002. AMOROZO, M.C.M.; GELY, A.L. Uso de plantas medicinais por caboclos do baixo Amazonas, Barcarena, PA, Brasil. Boletim do Museu Paraense Emílio Goeldi, Série Botânica, v.4, n.1, p.47-131, 1988.

AMOROZO, M.C.M.; REIS, M.S.; FERRI, P.H. AAbordagem etnobotânica na pesquisa de plantas medicinais. In: DI STASI, L.C. (Org.). Plantas medicinais: arte e ciência um guia de estudo interdisciplinar. São Paulo: Editora da Universidade Estadual Paulista, 1996. p.47-68.

CALÁBRIA, L. et al. Levantamento etnobotânico e etnofarmacológico de plantas medicinais em Indianópolis,
Minas Gerais, Brasil. Revista Brasileira de Plantas Medicinais, v.10, n.1, p.49-63, 2008.

CASTELLUCCI, S. et al. Plantas medicinais relatadas pela comunidade residente na Estação Ecológica de Jataí, município de Luís Antonio/SP: uma abordagem etnobotânica. Revista Brasileira de Plantas Medicinais, v.3, n.1, p.51-60, 2000.

DUKE, J.A. Handbook of medicinal herbs. Boca Raton: CRC, 1989, 677p.

FONSECA, V.S.; SÁ, C.F.C. Situación de los estudios etnobotánicos en ecosistemas costeros de Brasil. In: MEMORIAS DEL SIMPOSIO ECUATORIANO DE ETNOBOTÁNICA Y BOTÁNICA ECONOMICA, 2., 1997, Arraial do Cabo. Anais... Arraial do Cabo: Serviço Social Rural, 1997. p.57-81.

HANAZAKI, N.; LEITÃO FILHO, H.F.; BEGOSSI, A. Uso de recursos na Mata Atlântica: o caso da Ponta do Almada. Interciência, v.21, n.6, p.268-76, 1996.

INSTITUTO BRASILEIRO DE GEOGRAFIA E ESTATÍSTICA (IBGE). Censo Demográfico 2007. Juiz de Fora. Minas Gerais. Visita Pessoal em 6 abr. 2010.

KFFURI, C.W. Etnobotânica de plantas medicinais no município de Senador Firmino, Minas Gerais. 2008. 88p. Dissertação (Mestrado em Fitotecnia) - Universidade Federal de Viçosa, Viçosa.

MAGALHÃES, V.C. et al. Levantamento etnobotânico na comunidade rural Sapucaia em Santo Antônio de Jesus, Recôncavo da Bahia - BA. Revista Brasileira de Agroecologia, v.4, n.2, p.2071-4, 2009.

MARODIN, S.M.; BAPTISTA, L.R.M. Plantas utilizadas como medicinais no município de Dom Pedro de Alcântara, Rio Grande do Sul, Brasil. Iheringia, Série Botânica, v.56, n.1, p.131-46, 2001.

MARTINS, E.R. et al. Plantas medicinais. Viçosa: Editora da Universidade Federal de Viçosa, 1994, 220p.

MATOS, F.J.A. Plantas medicinais: guia de seleção e emprego de plantas usadas em fitoterapia no nordeste do Brasil. 2.ed. Fortaleza: Imprensa Universitária da Universidade Federal do Ceará, 2000. 144p.

MENON-MIYAKE, M.A. et al. Inquérito sobre o uso de plantas medicinais para tratamento de afecções otorrinolaringológicas entre pacientes de um hospital público terciário. Revista Brasileira de Otorrinolaringologia, v.70, n.2, p.43-55, 2004.

MING, L.C.; AMARAL JÚNIOR, A. Aspectos etnobotânicos de plantas medicinais na Reserva Extrativista "Chico Mendes". In: DALY, D.C.; SILVEIRA, M.; FERREIRA, E.J.L. (Eds.). Floristics and economic botany of Acre, Brazil. New York: The New York Botanical Garden. Disponível em: <http://www.nybg.org/bsci/acre/www1/ medicinal.html>. Acesso em: 10 abr. 2010.

MODESTO, P.R. Lima Duarte - Ano 92, v.2 - Síntese escrita e ilustrada dos fatos, históricos e tradições do município. Juiz de Fora: Esdeva, Empresa Gráfica S.A. 1976. 235p.

PARENTE, E.T.; ROSA, M.M.T. Plantas comercializadas como medicinais no município de Barra do Piraí, RJ. Rodriguésia, v.52, n.80, p.47-59, 2001.

PEREIRA, R.C.; OLIVEIRA, M.T.R.; LEMOS, G.C.S. Plantas utilizadas como medicinais no município de Campos de Goytacazes - RJ. Revista Brasileira de Farmacognosia, v.14, n.1, p.37-40, 2004.

PHILLIPS, O.; GENTRY, A.H. The useful plants of 
Tambopata, Peru II: Aditional hypothesis testing in quantitative ethnobotany. Economic Botany, n.47, v.1, p.33-43, 1993.

PINTO, D.P.P.; AMOROZO, M.C.M.; FURLAN, A. Conhecimento popular sobre plantas medicinais em comunidades rurais de mata atlântica - Itararé, BA, Brasil. Acta Botanica Brasilica, v.20, n.4, p.751-62, 2006.

SHARDONG, R.M.F.; CERVI, A.C. Estudo etnobotânico das plantas de uso medicinal e místico na comunidade de São Benedito, bairro São Francisco, Campo Grande, MS. Acta Biológica Paranaense, v.29, n.1/4, p.187-217, 2000.

SILVA-ALMEIDA, M.F.; AMOROZO, M.C.M. Medicina popular no Distrito de Ferraz, Município de Rio Claro, SP. Brazilian Journal of Ecology, v.2, n.1, p.36-46, 1998. SILVA, F.S. et al. Levantamento etnobotânico das plantas medicinais da zona rural do município de Piumhi, Minas Gerais. Revista Científica Eletrônica de Engenharia Florestal, v.3, n.6, p.1-4, 2005. Disponível em: <http://www.revista.inf.br/florestal06/ pages/artigos/ artigo03.pdf $>$. Acesso em: $10 \mathrm{abr}$. 2010.

SILVA, M.D.; DREVECK, S.; ZENI, A.L.B. Estudo etnobotânico de plantas medicinais utilizadas pela população rural no entorno do Parque Nacional da Serra do Itajaí - Indaial. Revista Saúde e Ambiente, v.10, n.2, p.54-64, 2009.

VENDRUSCOLO, G.S.; MENTZ, L.A. Levantamento etnobotânico das plantas utilizadas como medicinais por moradores do bairro Ponta Grossa, Porto Alegre, Rio Grande do Sul, Brasil. Iheringia, Série Botânica, v.61, n.1/2, p.83-103, 2006. 